\title{
Application of eupatilin in the treatment of osteosarcoma
}

\author{
YAN-YAN LI ${ }^{1}$, HAO WU ${ }^{2}$, YI-GUO DONG ${ }^{3}$, BO LIN ${ }^{3}$, GANG XU $^{3}$ and YU-BO MA ${ }^{3}$ \\ ${ }^{1}$ Department of Neurology, The Second People's Hospital of Mudanjiang, Mudanjiang, Heilongjiang 157013; \\ ${ }^{2}$ Department of Orthopedics, Sengong Hospital, Harbin, Heilongjiang 150040; ${ }^{3}$ Department of Orthopedics, Hongqi Hospital, \\ Mudanjiang Medical University, Mudanjiang, Heilongjiang 157011, P.R. China
}

Received July 8, 2014; Accepted May 22, 2015

DOI: $10.3892 / \mathrm{ol} .2015 .3563$

\begin{abstract}
. 5,7-dihydroxy-3',4',6-trimethoxyflavone, commonly known as eupatilin, is a traditional Asian medicinal plant, which is mainly used for the treatment of gastritis, as well as its use as an anti-inflammatory agent. Eupatilin is a bioactive compound; however, its effects on osteosarcoma (OS) have remained to be elucidated. Therefore, the present study aimed to investigate the effects of eupatilin on this malignant bone tumor, using the U-2 OS cell line. The experimental results revealed that eupatilin inhibited U-2 OS cell growth in a concentration-dependent manner and induced G2/M phase cell cycle arrest and apoptosis. Additionally, western blot analysis indicated that eupatilin was able to trigger the mitochondrial apoptotic pathway, demonstrated by the enhanced Bax/B cell lymphoma-2 ratio, decrease in mitochondrial membrane potential, release of cytochrome $c$, caspase-3 and -9 activation and poly(ADP-ribose)polymerase cleavage detected in the U-2 OS cells. These results indicated that eupatilin was able to inhibit U-2 OS cancer cell proliferation by the induction of apoptosis via the mitochondrial intrinsic pathway. Eupatilin may therefore represent a novel anticancer drug for use in the treatment of osteosarcoma.
\end{abstract}

\section{Introduction}

Osteosarcoma (OS) is considered to be one of the most common and aggressive primary bone tumors of the musculoskeletal system, and predominantly occurs in childhood and adolescence $(1,2)$. There are various potential treatments for OS, including radiotherapy, surgery and chemotherapy; however, the results of these available treatments remain unsatisfactory (3). Significant nephrotoxic and cardiotoxic side-effects are induced by chemopreventative medicines, thereby limiting the efficacy of their use in the treatment of OS (4). Manipulation of apoptosis is one of the major targets in the treatment of cancer.

Correspondence to: Mr. Yu-Bo Ma, Department of Orthopedics, Hongqi Hospital, Mudanjiang Medical University, 5 Tongxiang Road, Mudanjiang, Heilongjiang 157011, P.R. China

E-mail: mayubo198@gmail.com

Key words: eupatilin, osteosarcoma, apoptosis, anticancer activity
Apoptosis describes genetically-dependent programmed cell death type I, and is characterized by cell shrinkage, signal transduction (5), nucleic condensation $(6,7)$ and DNA and cellular protein degradation (8). Previous studies have revealed that few therapeutic treatments exist that result in an enhanced ability of human tumor cell lines to undergo apoptosis $(9,10)$. Therefore, the development of novel agents to induce or increase the phenomenon of apoptosis present a promising approach for the development of cancer treatments. Novel inducers of apoptosis may provide alternative and efficacious therapeutic anticancer strategies.

Flavonoids are associated with multiple biological effects, including antitumor, anti-oxidation, anti-inflammation, antiviral and hepatoprotective activities, as well as in the prevention of cardiovascular diseases (11-16). Eupatilin (5,7-dihydroxy-3',4',6-trimethoxyflavone) is extracted from Artemisia asiatica (A. asiatica) Nakai, and this isolated flavonoid contains pharmacologically active ingredients. Eupatilin has been demonstrated to exert anticancer, anti-oxidative and anti-inflammatory effects (17). A previous report indicated that Stillen $^{\mathrm{TM}}$ (DA-9601), produced from the ethanol extract of A. asiatica, contained the pharmacologically active flavonoid compound eupatilin (17). DA-9601 demonstrated cytoprotective effects against gastric mucosal damage and ulcerative proctitis. Eupatilin has exhibited positive effects in the treatment of oxidant-dependent gastric disorders (18). Eupatilin, apigenin, wogonin and baicalein are all members of the same family of flavonoids. Although the flavones, apigenin, wogonin and baicalein, have previously been used in the treatment of OS (19-21), the molecular mechanisms underlying eupatilin-mediated apoptosis of the U-2 OS cell line have remained to be elucidated. Therefore, the present study aimed to aid the elucidation of the underlying mechanism involved in eupatilin-induced apoptosis of U-2 OS cells. This was achieved via cytotoxicity experiments, apoptosis studies and the analysis of changes in protein expression associated with apoptotic cell death.

\section{Materials and methods}

Reagents. Eupatilin was provided by Dong-A Pharmaceutical Co. Ltd (Cheoin-gu, South Korea). Antibodies against PARP, Bax, Bcl-2 and cytochrome $c$ were purchased from Santa Cruz Biotechnology, Inc. (Dallas, TX, USA). Caspase inhibitors Z-DEVE-FMK, Z-IETD-FMK and Z-LEHD-FMK for 
caspase-3, caspase- 8 and caspase-9 were obtained from R\&D Systems (Minneapolis, MP, USA). These inhibitors were dissolved in dimethyl sulfoxide (DMSO; Xi'an Chemical Co., Ltd., Boaji, China) and diluted prior to use in cell culture. The present study was approved by the ethics committee board of Mudanjiang Medical University (Mudanjiang, China). The remaining reagents and solvents used were of analytical grade and purchased from Xi'an Chemical Co., Ltd.

Cells and culture. The U-2 OS human OS cells were purchased from the Cell Bank of Shanghai Institute of Biochemistry and Cell Biology, Chinese Academy of Sciences (Shanghai, China). The cells were maintained in RPMI-1640 medium supplemented with fetal calf serum (FCS; 10\%), glutamine (2 $\mathrm{mM})$, penicillin $(100 \mathrm{U} / \mathrm{ml})$ and streptomycin $(10 \mu \mathrm{g} / \mathrm{ml})$ in a humidified atmosphere at $37^{\circ} \mathrm{C}$ with $5 \% \mathrm{CO}_{2}$.

MTT assay. The viability of U-2 OS cells was determined using an MTT assay. U-2 OS cells were seeded at a density of $5 \times 10^{4}$ cells/well in 96-well culture plates. Each well contained $100 \mu \mathrm{l}$ medium supplemented with $10 \% \mathrm{FCS}$, and the cells were incubated at $37^{\circ} \mathrm{C}$ for $24 \mathrm{~h}$ prior to treatment with various concentrations of eupatilin. Following $24 \mathrm{~h}$ of incubation, the medium was removed and replaced with $10 \%$ FCS containing various concentrations of eupatilin (0, 50, 100, 200 and $400 \mu \mathrm{g} / \mathrm{ml}$ ) and incubated at $37^{\circ} \mathrm{C}$ for $96 \mathrm{~h}$. Subsequently, $50 \mu \mathrm{l}$ MTT solution was added to each well and incubated for a further $4 \mathrm{~h}$ as described previously (22). The formazan crystals obtained were dissolved in $100 \mu \mathrm{l}$ DMSO and the absorbance was recorded using an ELISA microplate reader (model 550; Bio-Rad, Laboratories, Inc., Hercules, CA, USA) at a wavelength of $570 \mathrm{~nm}$.

Annexin V-fluorescein isothiocyanate (FITC) and propidium iodide (PI) double staining. Cell apoptosis was detected using Annexin V-FITC/PI double staining. In brief, $1 \times 10^{5}$ untreated (control) or treated cells were harvested following trypsinization and centrifugation ( $500 \mathrm{x} \mathrm{g}$ for $5 \mathrm{~min}$ ). The cells were then washed twice with ice-cold phosphate-buffered saline (PBS) and stained with an Annexin V-FITC/PI apoptosis kit (BD Pharmingen, San Diego, CA, USA), according to the manufacturer's instructions. Subsequently, the samples were analyzed using the FACS Calibur flow cytometer (BD Biosciences, Franklin Lakes, NJ, USA). Double-staining was used for the quantification of the apoptosis of U-2 OS cells following treatment with eupatilin, by measurement of phosphatidylserine expression on the outer surface of the plasma membrane identified by Annexin V-FITC binding. The results of the assay were analyzed with the exclusion of PI, the plasma membrane integrity probe (23).

Flow cytometry and cell cycle analysis. Eupatilin-treated cells were harvested using $0.25 \%$ trypsin and then washed with PBS twice prior to fixation with $70 \%$ ethanol for $\sim 30 \mathrm{~min}$ at $4^{\circ} \mathrm{C}$. The cells were pelleted by centrifuging at $500 \mathrm{x} \mathrm{g}$ for $5 \mathrm{~min}$ and resuspended in $1 \mathrm{ml}$ PBS containing $100 \mu \mathrm{l}$ RNase $(10 \mathrm{mg} / \mathrm{ml})$ and $100 \mu \mathrm{l} \mathrm{PI}(0.5 \mathrm{mg} / \mathrm{ml})$ for $\sim 20 \mathrm{~min}$ at $37^{\circ} \mathrm{C}$ for cytoplasmic or nuclear DNA staining. The stained cells were then analyzed for DNA content using the FACS Calibur as previously described (24). Annexin V- and PI-positive cells were considered to be necrotic type cells, whereas Annexin-V positive and PI-negative cells were considered to be apoptotic cells.

Mitochondrial membrane potential $(\Delta \Psi m)$ determination. The $\Delta \Psi \mathrm{m}$ of the U-2 OS cells was analyzed by flow cytometry, using rhodamine 123 (Rh123), a fluorescent dye which has been shown to be selectively accumulated within the mitochondria of live cells (25). In brief, the eupatilin-treated and untreated cells were incubated with Rh123 dye $(1 \mathrm{mg} / \mathrm{ml}$ in DMSO) for $30 \mathrm{~min}$ at $37^{\circ} \mathrm{C}$ in $5 \% \mathrm{CO}_{2}$. Subsequently, the cells were washed twice with $\mathrm{PBS}$, resuspended in PBS, stained with $2 \mu \mathrm{g} / \mathrm{ml}$ PI and immediately subjected to flow cytometric analysis. The loss of $\Delta \Psi \mathrm{m}$ was calculated as a percentage using CellQuest ${ }^{\mathrm{TM}}$ software (version 5.1; BD Biosciences).

Caspase-3, - 8 and -9 activities. The activities of caspase-3, -8 and -9 were evaluated using a caspase colorimetric assay kit (BioTek Instruments, Inc., Winooski, VT, USA) according to the manufacturer's instructions. U-2 OS cells were seeded in 12-well culture plates at a density of $2 \times 10^{5}$ cells/well prior to incubation with eupatilin for $48 \mathrm{~h}$. The cells were then harvested, lysed with lysis buffer for $\sim 5 \mathrm{~min}$ in an ice bath and then centrifuged at 10,000 x g for $10 \mathrm{~min}$. Subsequently, the reaction buffer was added to the supernatant solutions containing the proteins $(100 \mu \mathrm{g})$. Caspase-3, -8 and -9 colorimetric substrates (5 $\mu$ l each) were then added for $2 \mathrm{~h}$ at $37^{\circ} \mathrm{C}$ in a $\mathrm{CO}_{2}$ incubator, prior to quantification of the optical density (OD) of the mixture at $405 \mathrm{~nm}$ using a spectrophotometer. Their respective activities were expressed relative to the theoretical OD value, calculated using the Sigma-Aldrich Caspase 9 Assay Kit, Colorimetric Technical Bulletin (www.sigmaaldrich. com/content/dam/sigma-aldrich/docs/Sigma/Bulletin/casp8cbul.pdf).

Western blot analysis. Cells were subjected to eupatilin treatment, and cell proteins were subsequently obtained by incubation for $1 \mathrm{~h}$ in $200 \mu \mathrm{l}$ lysis buffer containing $\mathrm{NaCl}$ (300 mM), Tris HCl (50 mM; pH 7.6), Triton X-100 (0.5\%), phenylmethanesulfonyl fluoride $(2 \mathrm{mM})$, aprotinin $(2 \mu \mathrm{l} / \mathrm{ml})$ and leupeptin $(2 \mu \mathrm{l} / \mathrm{ml})$ at $4^{\circ} \mathrm{C}$. A bicinchoninic acid protein assay kit (Pierce Biotechnology, Inc.; Thermo Fisher Scientific, Rockford, IL, USA) was used to quantify the protein expression levels, according to the manufacturer's instructions. Equal quantities of each protein $(20 \mu \mathrm{g})$ were separated by $12 \%$ SDS-PAGE and then electrotransferred onto polyvinylidene difluoride membranes. The membranes were then incubated for $1 \mathrm{~h}$ with PBS containing 5\% non-fat milk as a blocking solution at room temperature, prior to incubation with polyclonal rabbit anti-mouse poly(ADP-ribose)polymerase (PARP; 1:1,000 dilution; cat no. 9542), B cell lymphoma-2 (1:1,000 dilution; cat no. 2876), Bcl-2-like protein 4 (Bax; 1:1,000 dilution; cat no. 2772) and cytochrome $c(1: 1,000$ dilution; cat no. 4272) antibodies (all from Cell Signaling Technology, Inc., Danvers, MA, USA) diluted with blocking solution at $4^{\circ} \mathrm{C}$ overnight. The membranes were subsequently incubated with horseradish peroxidase-conjugated rabbit anti-mouse secondary antibody $(1: 2,000-5,000)$ for $\sim 2 \mathrm{~h}$ at 


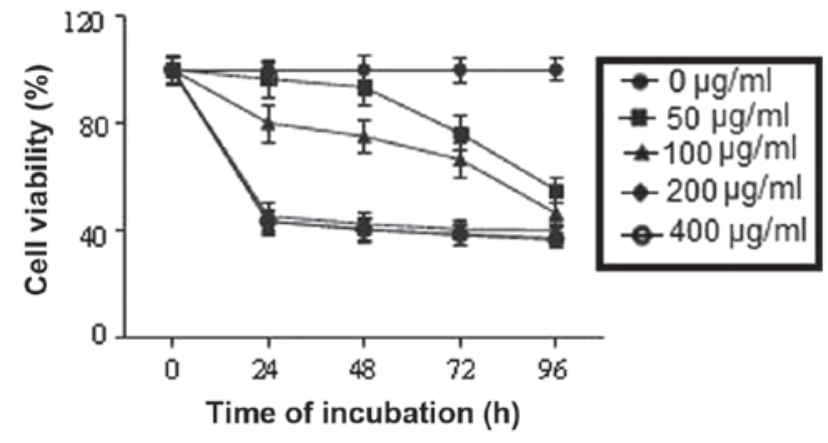

Figure 1. Effects of eupatilin on the growth of U-2 osteosarcoma cells. The data are presented as the mean \pm standard deviation of triplicate experiments.
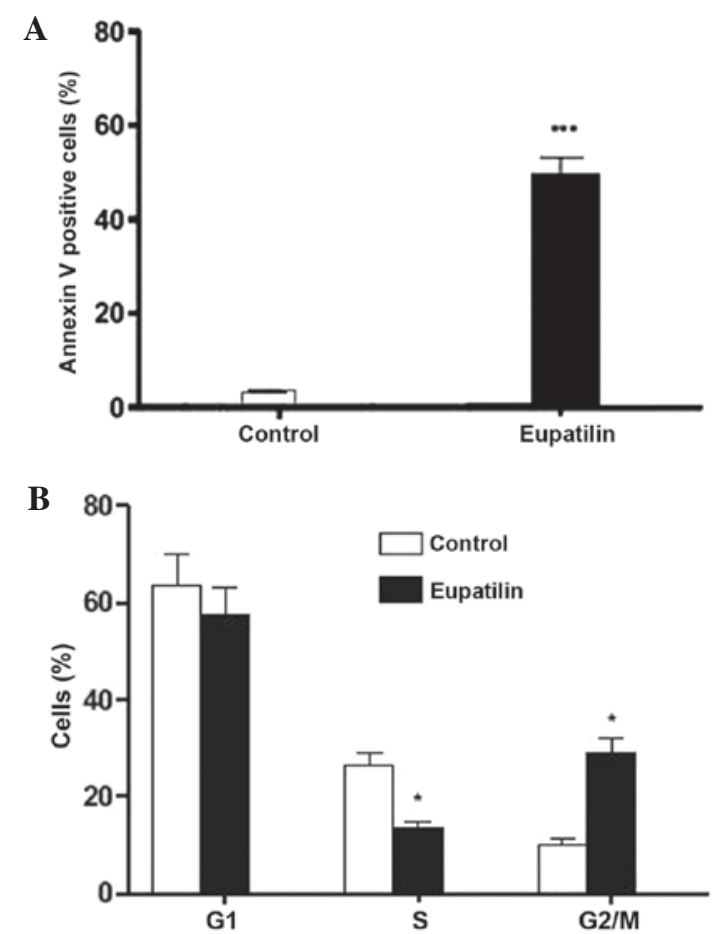

Figure 2. Eupatilin alters the cell cycle distribution and induces apoptosis of U-2 OS cells. (A) Eupatilin $(100 \mu \mathrm{g} / \mathrm{ml})$ induced significant apoptosis of U-2 OS cells. (B) Eupatilin $(100 \mu \mathrm{g} / \mathrm{ml})$ induced alterations in cell cycle phase distribution in U-2 OS cells. Data are presented as the mean \pm standard deviation of triplicate experiments. ${ }^{*} \mathrm{P}<0.05,{ }^{* * * *} \mathrm{P}<0.001 \mathrm{vs}$. control (untreated cells). OS, osteosarcoma.

room temperature. The developed immunoblots were then visualized with an enhanced chemiluminescence detecting system (GE Healthcare Life Sciences, Chalfont, UK). Expression was analyzed relatively, based on the ratio between the target protein and that of polyclonal rabbit $\beta$-actin $(1: 1,000$ dilution; cat no. 4967; Cell Signaling Technology, Inc.).

Statistical analysis. All the quantitative results obtained are presented as the mean \pm standard deviation. Student's t-test was used to calculate statistical differences between the control and eupatilin-treated cells, using GraphPad Prism 3.03 software (GraphPad Software, Inc., La Jolla, CA, USA) and $\mathrm{P}<0.05$ was considered to indicate a statistically significant difference. All the studies were performed at least in triplicate.

\section{Results}

Eupatilin inhibits growth of U-2 OS cells. The effects of eupatilin on U-2 OS cell proliferation were evaluated by MTT assay. The cells were treated with various concentrations of eupatilin $(0,50,100,200$ and $400 \mu \mathrm{g} / \mathrm{ml})$ for various time-periods $(0,24,48,72$ and $96 \mathrm{~h})$ and cell proliferation under these conditions was evaluated. The results revealed a dose-dependent inhibitory effect of eupatilin on U-2 OS cell proliferation $24 \mathrm{~h}$ post-treatment (Fig. 1). The inhibitory effect of eupatilin was demonstrated to be significant at a concentration of $100 \mu \mathrm{g} / \mathrm{ml}$, whereas the most marked inhibition was observed in cells which were treated with eupatilin at concentrations of 200 and $400 \mu \mathrm{g} / \mathrm{ml}$.

These results confirmed the antiproliferative effect of eupatilin on U-2 OS cells, and in order to elucidate the mechanism underlying this effect, eupatilin at a concentration of $100 \mu \mathrm{g} / \mathrm{ml}$ was selected for use in the subsequent experiments.

Eupatilin alters the cell cycle distribution and induces apoptosis of U-2 OS cells. To ascertain whether eupatilin inhibited U-2 OS cell proliferation via induction of apoptosis, the cells were treated with eupatilin and then subjected to flow cytometric analysis. The results revealed a significant increase in Annexin V-FITC cell binding following $100 \mu \mathrm{g} / \mathrm{ml}$ eupatilin treatment, compared with that of the control cells, indicating the initiation of apoptosis. Fig. 2A indicates that the apoptotic cell proportion was significantly increased from $3.23 \%$ in untreated U-2 OS cells to $49.75 \%$ in eupatilin-treated U-2 OS cells. These results confirmed that the cell death observed in U-2 OS cells following eupatilin treatment occurred via the induction of apoptosis. In addition, flow cytometric analysis revealed that eupatilin treatment for $24 \mathrm{~h}$ significantly reduced the proportion of cells in $\mathrm{S}$ phase, compared with that of the control cells (Fig. 2B). Furthermore, elevated accumulation of cells in the $\mathrm{G} 2 / \mathrm{M}$ apoptotic phase was observed, with respect to control cells, while the cell population in G1 phase demonstrated a slight decrease. These results revealed that the eupatilin responses of U-2 OS cells are correlated with apoptotic cell death.

Eupatilin induces mitochondrial dysfunction and cytochrome c release. In order to confirm whether mitochondrial dysfunction was involved in eupatilin-induced apoptosis, changes in $\Delta \Psi \mathrm{m}$ were evaluated using Rh123 fluorescent dye. Rh123 was used as it is able to cross the mitochondrial membrane and thus accumulates in the mitochondrial matrix. However, this accumulation only occurs when the transmembrane potential is maintained (26). As indicated in Fig. 3A, following exposure of U-2 OS cells to $100 \mu \mathrm{g} / \mathrm{ml}$ eupatilin for $24 \mathrm{~h}$, a significant reduction in $\Delta \Psi \mathrm{m}$ was observed. The release of cytochrome $c$ from the mitochondria to the cytosol is typically associated with $\Delta \Psi \mathrm{m}$ depolarization (27). In addition, cytochrome $c$ has been demonstrated to have a vital role in apoptosis $(28,29)$. Therefore, the expression of cytochrome $c$ was analyzed by western blotting. Fig. 3B indicates an increase in cytosolic cytochrome $c$ and a decrease in mitochondrial cytochrome $c$ in eupatilin-treated cells, when compared with control cells. These results indicated that 
A

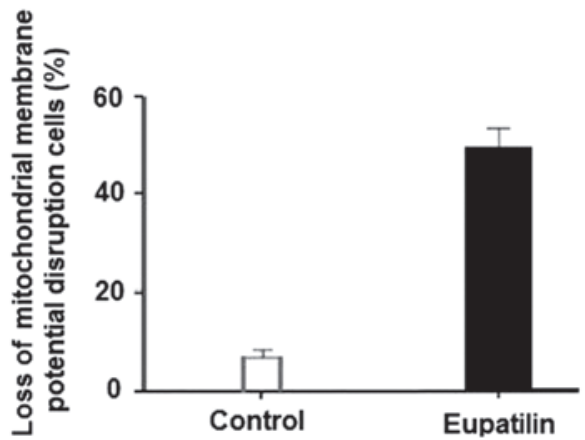

B

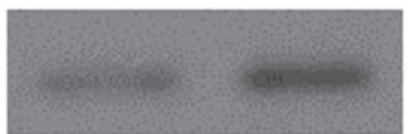

Cytosolic cytochrome c

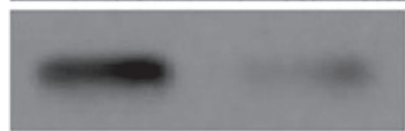

Mitochondrial

cytochrome c

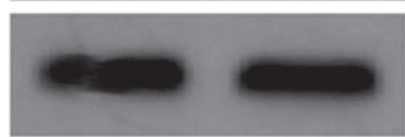

$\beta$-Actin

Control

Eupatilin

Figure 3. Eupatilin induces mitochondrial dysfunction and cytochrome $c$ release. (A) Eupatilin $(100 \mu \mathrm{g} / \mathrm{ml})$-induced a significant reduction in the mitochondrial membrane potential in U-2 OS cells. (B) Eupatilin $(100 \mu \mathrm{g} / \mathrm{ml})$-induced release of cytochrome $c$ into the cytosol of U-2 OS cells. Data are presented as the mean \pm standard deviation of triplicate experiments. "P<0.05 vs. control. OS, osteosarcoma.

eupatilin-induced apoptosis involves mitochondrial dysfunction, associated with a loss of $\Delta \Psi \mathrm{m}$ and cytosolic cytochrome $c$ release.

Eupatilin induces caspase activation and PARP cleavage in $U-2$ OS cells. Subsequently, the effects of eupatilin on caspase-3, -8 and -9 activation and PARP cleavage were evaluated, in order to determine the death receptor involvement and mitochondrial pathways in eupatilin-induced apoptosis. The results revealed that eupatilin treatment of U-2 OS cells for $24 \mathrm{~h}$ induced activation of caspase- 3 and -9 , but not caspase-8 (Fig. 4A). Furthermore, as indicated in Fig. 4B, an increase in PARP cleavage was detected following eupatilin treatment. To further investigate the role of caspase activation in eupatilin-induced apoptosis, the effects of caspase inhibitors z-DEVE-FMK, Z-IETD-FMK, and Z-LEHD-FMK for caspase-3, -8 and -9 on apoptosis in U-2 OS cells were evaluated. Significant inhibition of eupatilin-induced apoptosis was observed following pretreatment with caspase- 3 and -9 inhibitors, whereas the levels of early apoptosis remained unchanged with respect to caspase- 8 inhibition (data not shown). These observations suggested that eupatilin induced caspase-dependent apoptosis in U-2 OS cells via a mitochondrial-dependent pathway.

Eupatilin upregulates Bax and downregulates Bcl-2 in U-2 OS cells. The effects of eupatilin on Bax and Bcl-2 expression in U-2 OS cells were subsequently examined via analysis of Bax and Bcl-2 protein expression levels following $24 \mathrm{~h}$ of treatment. Western blot analysis indicated a marked increase in Bax
A

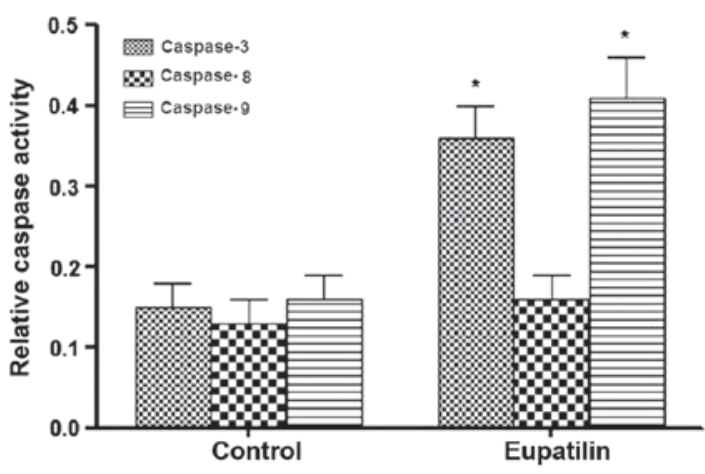

B

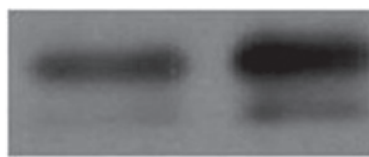

PARP

Cleaved PARP

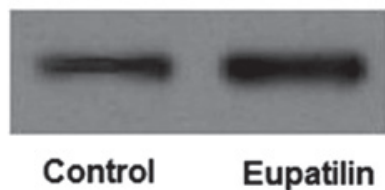

$\beta$-Actin

Figure 4. Eupatilin induces caspase activation and PARP cleavage in U-2 OS cells. (A) Eupatilin $(100 \mu \mathrm{g} / \mathrm{ml})$ enhanced the activation of caspase- 8 and -9 but not caspase-3. (B) Eupatilin induced PARP cleavage in U-2 OS cells. Data are presented as the mean \pm standard deviation of triplicate experiments. ${ }^{*} \mathrm{P}<0.05$ vs. control. OS, osteosarcoma.

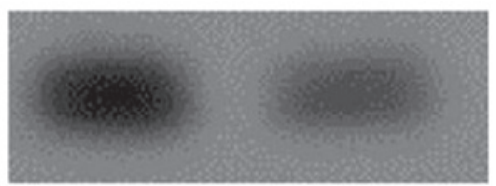

$\mathrm{Bcl}-2$

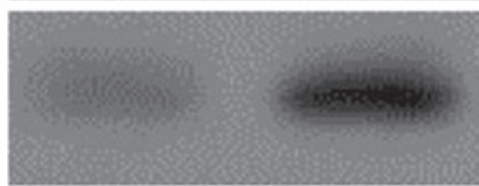

Bax

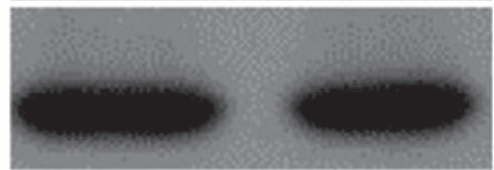

$\beta$-Actin

Control

Eupatilin

Figure 5. Eupatilin-mediated upregulation of Bax and downregulation of Bcl-2 in U-2 osteosarcoma cells identified by western blotting assay. Data are presented as the mean \pm standard deviation of triplicate experiments. ${ }^{*} \mathrm{P}<0.05$ vs. control.

expression levels in eupatilin-treated cells, whereas a significant decrease was observed in Bcl-2 expression (Fig. 5). This high ratio of Bax/Bcl-2 may contribute to the induction of apoptosis by eupatilin via the mitochondrial-dependent pathway.

\section{Discussion}

Apoptosis is a genetically mediated mechanism of type 1 programmed cell death. Shrinkage of cells, plasma membrane blebbing and chromatin condensation associated with DNA 
cleavage into ladders comprise the major characteristics of apoptosis $(30,31)$.

Accumulating evidence has indicated that the antitumor effects of a wide variety of compounds and herbal medicines obtained from natural products, which exhibit anticancer effects, are able to induce apoptosis in numerous human tumor cell lines $(32,33)$. Previous studies have indicated a cytoprotective effect of A. asiatica ethanol extract against gastric mucosa damage and ulcerative colitis. A. asiatica is also known to be effective in the treatment of oxidant-dependent gastric disease $(18,34)$. In the present study, the anticancer efficacy of eupatilin and its underlying mechanism in human osteosarcoma $\mathrm{U}-2$ OS cells, in vitro, was evaluated. The MTT assay results demonstrated that eupatilin effectively suppressed the proliferation of U-2 OS cells in a concentration- and time-dependent response. The results of FACS analysis indicated that eupatilin induced apoptosis in U-2 OS cells and also increased the proportion of cells at $\mathrm{G} 2 / \mathrm{M}$ phase. These results demonstrated that the eupatilin was able to potently trigger apoptosis in U-2 OS cells. Subsequently, the present study aimed to identify the apoptotic mechanism the effects of eupatilin in U-2 OS cells. Mitochondrial integrity disruption is one of the most common and earliest intracellular events to occur following apoptosis initiation (35). Increasing evidence suggests that this mitochondrial dysfunction may activate particular cell signaling pathways, resulting in the induction of apoptosis, as well as the reduction in $\Delta \Psi \mathrm{m}$ associated with mitochondrial dysfunction. For this reason, the loss of $\Delta \Psi \mathrm{m}$ is significant during mitochondrial-dependent apoptosis (36-38), as, in turn, it induces the efflux of cytochrome $c$ into the cytosol from mitochondria. Following release into the cytosol, cytochrome $c$ is able to initiate caspase activation, which aids termination of the cells by apoptosis. The results of the present study indicated that eupatilin exposure induced $\Delta \Psi \mathrm{m}$ loss and an increase in cytochrome $c$ release to the cytosol from the mitochondria in U-2OS cells, which indicated that eupatilin-induced cell death potentially occurred via the mitochondrial apoptotic pathway.

Previous studies have indicated that the mitochondria-mediated pathway for apoptosis is regulated by proteins of the Bcl-2 family $(39,40)$. It was suggested that the balance between Bax and Bcl-2 is significant in conferring cell susceptibility to apoptosis (41). In order to further elucidate the mechanisms underlying the anticancer effects of eupatilin, the expression levels of two major apoptotic signaling proteins, $\mathrm{Bax}$ and $\mathrm{Bcl}-2$, were evaluated. An increase in Bax:Bcl-2 ratio was observed in the eupatilin-treated cells, suggesting that eupatilin-induced apoptosis was associated with alterations in Bax and Bcl-2 expression. Apoptosis is controlled by cell suicide mechanisms induced by specific external and internal signals. Currently, two major pathways associated with the induction of apoptosis are known: The mitochondrial signaling pathway and the cell-suicide receptor pathway, controlled by caspase-9 and -8, respectively (42). Accumulating evidence has revealed the essential roles of caspase action in the apoptotic cascade. In the mitochondrial pathway (the intrinsic pathway), cytochrome $c$ is released from the mitochondria to the cytosol, and is then able to bind with Apaf-1 and activate caspase-9. Activated caspase- 9 subsequently activates the downstream caspases, caspase- 3 and/or -7 , which in turn aids the cleavage or degradation of various cellular substances, including PARP, inducing apoptosis (43-48). In the cell suicide pathway (the extrinsic pathway), the death receptors that are present on the cell surface (Fas/FasL) are activated, triggering caspase- 8 activation $(49,50)$. To elucidate which of these signaling pathways was involved in eupatilin-induced apoptosis, the apoptosis-associated protein expression of casapases-3, -8, -9 and PARP were investigated in U-2 OS cells. The results indicated that apoptosis was induced by caspase- 3 and -9 activation, but not caspase- 8 activation. Furthermore, the identification of PARP cleavage confirmed the participation of caspase-3 in the induction of apoptosis in the eupatilin-treated cells. In addition, apoptosis was significantly attenuated in the presence of Z-DEVE-FMK and Z-LEHD-FMK inhibitors of caspase-3 and -9 , respectively. By contrast, the number of eupatilin-induced early apoptotic U-2 OS cells remained unchanged with respect to caspase- 8 inhibitor response. These results revealed that eupatilin-induced apoptosis in U-2 OS cells occurred via the intrinsic pathway, associated with caspase- 3 and -9 activation and PARP cleavage.

In conclusion, the results of the present study indicated that eupatilin perturbed U-2 OS cell growth in a dose-dependent fashion. The decrease in cell viability occurred as a result of $\mathrm{G} 2 / \mathrm{M}$ phase cell cycle arrest and the induction of apoptosis, hallmarks of the intrinsic apoptotic pathway in U-2 OS cells. Furthermore, eupatilin triggered apoptosis via the mitochondria-mediated pathway, which involved the inhibition of Bcl-2 expression and the induction of Bax expression for the degradation of the outer mitochondrial membrane and release of cytochrome $c$. Eupatilin also induced caspase-3 and -9 activation, but not caspase- 8 activation. Finally, eupatilin induced PARP cleavage, which is the substrate for caspase-3 activation following eupatilin treatment. In vivo studies of eupatilin effects on U-2 OS xenografts in nude tumor mice are currently underway. The results of the present study aid the elucidation of the molecular mechanisms involved in the antitumor effects of eupatilin in OS, and confirmed that eupatilin may be effective as a drug for use in the treatment of OS.

\section{References}

1. Longhi A, Errani C, De Paolis M, Mercuri M, Bacci G: Primary bone osteosarcoma in the pediatric age: State of the art. Cancer Treat Rev 32: 423-436, 2006.

2. Chou AJ and Gorlick R: Chemotherapy resistance in osteosarcoma: current challenges and future directions. Expert Rev Anticancer Ther 6: 1075-1085, 2006.

3. Anderson PM, Tomaras M and McConnell K: Mifamurtide in osteosarcoma - a practical review. Drugs Today (Barc) 46: 327-337, 2010.

4. D'Adamo DR: Appraising the current role of chemotherapy for the treatment of sarcoma. Semin Oncol 38 (Suppl 3): S19-S29, 2011.

5. Ashkenazi A and Dixit VM: Death receptors: Signaling and modulation. Science 281: 1305-1308, 1998.

6. Orlov SN, Dam TV, Tremblay J and Hamet P: Apoptosis in vascular smooth muscle cells: Role of cell shrinkage. Biochem Biophys Res Commun 221: 708-715, 1996.

7. Shimizu T, Maeno E and Okada Y: Prerequisite role of persistent cell shrinkage in apoptosis of human epithelial cells. Sheng Li Xue Bao 59: 512-516, 2007.

8. Thornberry NA and Lazebnik Y: Caspases: Enemies within. Science 281: 1312-1316, 1998.

9. Barry MA,Behnke CA and Eastman A: Activation of programmed cell death (apoptosis) by cisplatin, other anticancer drugs, toxins and hyperthermia. Biochem Pharmacol 40: 2353-2362, 1990. 
10. Hoffman B and Liebermann DA: Molecular controls of apoptosis: Differentiation/growth arrest primary response genes, proto-oncogenes and tumor suppressor genes as positive and negative modulators. Oncogene 9: 1807-1812, 1994.

11. Guo Q, Zhao L, You Q, Yang Y, et al: Anti-hepatitis B virus activity of wogonin in vitro and in vivo. Antiviral Res 74: 16-24, 2007.

12. Cárdenas M, Marder M, Blank VC and Roguin LP: Antitumor activity of some natural flavonoids and synthetic derivatives on various human and murine cancer cell lines. Bioorg Med Chem 14: 2966-2971, 2006.

13. Burda S and Oleszek W: Antioxidant and antiradical activities of flavonoids. J Agric Food Chem 49: 2774-2779, 2001.

14. González-Gallego J, Sánchez-Campos S and Tunón MJ: Anti-inflammatory properties of dietary flavonoids. Nutr Hosp 22: 287-293, 2007.

15. Yao P, Nussler A, Liu L, Hao L, et al: Quercetin protects human hepatocytes from ethanol-derived oxidative stress by inducing heme oxygenase-1 via the MAPK/Nrf2 pathways. J Hepatol 47: 253-261, 2007.

16. Tijburg LB, Mattern T, Folts JD, Weisgerber UM and Katan MB: Tea flavonoids and cardiovascular disease: A review. Crit Rev Food Sci Nutr 37: 771-785, 1997.

17. Seo HJ and Surh YJ: Eupatilin: A pharmacologically active flavone derived from Artemisia plants, induces apoptosis in human promyelocytic leukemia cells. Mutat Res 496: 191-198, 2001.

18. Huh K, Kwon TH, Shin US, Kim WB, et al: Inhibitory effects of DA-9601 on ethanol-induced gastrohemorrhagic lesions and gastric xanthine oxidase activity in rats. J Ethnopharmacol 88: 269-273, 2003.

19. Lin CC, Chuang YJ, Yu CC, Yang JS, Lu CC, Chiang JH, Lin JP, Tang NY, Huang AC and Chung JG: Apigenin induces apoptosis through mitochondrial dysfunction in U-2 OS human osteosarcoma cells and inhibits osteosarcoma xenograft tumor growth in vivo. J Agric Food Chem 60: 11395-11402, 2012.

20. Lin CC, Kuo CL, Lee MH, et al: Wogonin triggers apoptosis in human osteosarcoma U-2 OS cells through the endoplasmic reticulum stress, mitochondrial dysfunction and caspase-3-dependent signaling pathways. Int J Oncol 39: 217-224, 2011.

21. Ding L, He S and Sun X: HSP70 desensitizes osteosarcoma cells to baicalein and protects cells from undergoing apoptosis. Apoptosis 19: 1269-1280, 2014.

22. Moalic S, Liagre B, Labrousse F and Beneytout JL: Enhanced apoptosis in retrovirally transfected osteosarcoma cells after exposure to sodium butyrate. Int J Oncol 16: 695-700, 2000.

23. van Engeland M, Nieland LJ, Ramaekers FC, Schutte B and Reutelingsperger CP: Annexin V-affinity assay: A review on an apoptosis detection system based on phosphatidylserine exposure. Cytometry 31: 1-9, 1998.

24. Moalic S, Liagre B, Le Bail JC and Beneytout JL: Dose-dependent modulation of apoptosis and cyclooxygenase-2 expression in human 1547 osteosarcoma cells by NS-398, a selective cyclooxygenase-2 inhibitor. Int J Oncol 18: 533-540, 2001.

25. Cao J, Liu Y, Jia L, Zhou HM, Kong Y, Yang G, et al: Curcumin induces apoptosis through mitochondrial hyperpolarization and mtDNA damage in human hepatoma G2 cells. Free Radic Biol Med 43: 968-975, 2007.

26. Johnson LV, Walsh ML, Bockus BJ and Chen LB: Monitoring of relative mitochondrial membrane potential in living cells by fluorescence microscopy. J Cell Biol 88: 526-535, 1981.

27. Von Ahsen O, Waterhouse NJ, Kuwana T, Newmeyer DD and Green DR: The harmless release of cytochrome $c$. Cell Death Differ 7: 1192-1199, 2000.

28. Skulachev VP: Cytochrome $c$ in the apoptotic and antioxidant cascades. FEBS Lett 423: 275-280, 1998.

29. Green DR and Reed JC: Mitochondria and apoptosis. Science 281:1309-1312, 1998.
30. Chen X, Ko LJ, Jayaraman L and Prives C: p53 levels, functional domains and DNA damage determine the extent of the apoptotic response of tumor cells. Genes Dev 10: 2438-2451, 1996.

31. Yu Z, Chen J, Ford BN, Brackley ME and Glickman BW: Human DNA repair systems: An overview. Environ Mol Mutagen 33: 3-20, 1999.

32. Huh JE, Lee EO, Kim MS, Kang KS, Kim CH, Cha BC, et al: Penta-O-galloyl-beta-D-glucose suppresses tumor growth via inhibition of angiogenesis and stimulation of apoptosis: Roles of cyclooxygenase- 2 and mitogen-activated protein kinase pathways. Carcinogenesis 26: 1436-1445, 2005.

33. Taraphdar AK, Roy M and Bhattacharya RK: Natural products as inducers of apoptosis: Implication for cancer therapy and prevention. Curr Sci 80: 1387-1396, 2001

34. Ahn BO, Ko KH, Oh TY, Cho H, Kim WB, et al: Efficacy of use of colonoscopy in dextran sulfate sodium induced ulcerative colitis in rats: The evaluation of the effects of antioxidant by colonoscopy. Int J Colorectal Dis 16: 174-181, 2001.

35. Dikmen M, Ozturk N and Ozturk Y: The antioxidant potency of Punica granatum L. fruit peel reduces cell proliferation and induces apoptosis on breast cancer. J Med Food 14: 1638-1646, 2011.

36. Qi F, Li A, Zhao L, Xu H, Inagaki Y, Wang D, et al: Cinobufacini, an aqueous extract from Bufo bufo gargarizans Cantor, induces apoptosis through a mitochondria-mediated pathway in human hepatocellular carcinoma cells. J Ethnopharmacol 128: 654-661, 2010.

37. Kroemer G, Galluzzi L and Brenner C: Mitochondrial membrane permeabilization in cell death. Physiol Rev 87: 99-163, 2007.

38. Han J, Goldstein LA, Gastman BR and Rabinowich H: Interrelated roles for Mcl-1 and BIM in regulation of TRAIL-mediated mitochondrial apoptosis. J Biol Chem 281: 10153-10163, 2006.

39. Fu YR, YiZJ,Yan YR and QiuZY:Hydroxycamptothecin-induced apoptosis in hepatoma SMMC-7721 cells and the role of mitochondrial pathway. Mitochondrion 6: 211-217, 2006.

40. Green DR and Evan Gl: A matter of life and death. Cancer Cell 1: 19-30, 2002.

41. Walesnky LD: BCL-2 in the crosshairs: Tipping the balance of life and death. Cell Death Differ 13: 1339-1350, 2006.

42. Hui KK, Kanungo AK, Elia AJ and Henderson JT: Caspase-3 deficiency reveals a physiologic role for Smac/DIABLO in regulating programmed cell death. Cell Death Differ 18: 1780-1790, 2011.

43. Chang HY and Yang X: Proteases for cell suicide: Functions and regulation of caspases. Microbiol Mol Biol Rev 64: 821-846, 2000.

44. Stennicke HR and Salvesen GS: Properties of the caspases. Biochim Biophys Acta 1387: 17-31, 1998.

45. Cain K, Brown DG, Langlais C and Cohen GM: Caspase activation involves the formation of the aposome, a large (approximately $700 \mathrm{kDa}$ ) caspase-activating complex. J Biol Chem 274: 22686-22692, 1999.

46. Sun XM, MacFarlane M, Zhuang J, Wolf BB, Green DR and Cohen GM: Distinct caspase cascades are initiated in receptor-mediated and chemical-induced apoptosis. J Biol Chem 274: 5053-5060, 1999

47. Tang XL, Yang XY, Jung HJ, Kim SY, Jung SY, Choi DY, et al: Asiatic acid induces colon cancer cell growth inhibition and apoptosis through mitochondrial death cascade. Biol Pharm Bull 32: 1399-1405, 2009

48. Zou H, Li Y, Liu X and Wang X: An APAF-1 cytochrome $c$ multimeric complex is a functional apoptosome that activates procaspase-9. J Biol Chem 274: 11549-11556, 1999.

49. Debatin KM and Krammer PH: Death receptors in chemotherapy and cancer. Oncogene 23: 2950-2966, 2004.

50. Fulda S and Debatin KM: Extrinsic versus intrinsic apoptosis pathways in anticancer chemotherapy. Oncogene 25: 4798-4811, 2006. 